\title{
NPP Risk Assessments Results Dependence Study on the Composition of the Population Living Around the NPP (on the Example of Rostov and Kalinin NPP)
}

S.S. Zolotarev ${ }^{1}$, M.A. Berberova ${ }^{2}$

zolotarev@phystech.edu|maria.berberova@gmail.com

${ }^{1}$ Moscow Institute of Physics and Technology, Moscow, Russia;

${ }^{2}$ International Nuclear Safety Center, Moscow, Russia

Nuclear power plants, being complex technological systems, represent a source of increased risk, in particular, a specific risk of radiation exposure. Obtaining quantitative assessments of radiation risk is critical for risk reduction and accident prevention. Existing methods for assessing radiation risk do not take into account the influence of external factors, such as population composition, geographical features, anthropogenic environmental changes, etc. The result of the risk analysis is the assessment of physical and economic indicators for the Rostov and Kalinin NPPs, taking into account the age composition of the population, as the most significant parameter. Based on a comparison of the estimates obtained with the results without taking into account the age distribution, recommendations are given on the use of adjusted estimates when developing measures to reduce risk and mitigate the consequences for the most sensitive age groups of the population (1-12 years). The objective of the work is to modify the methodological approach to the calculation of radiation risk indicators of the population, taking into account the age composition and the practical application of the formulas for assessing the physical and economic indicators of damage to real objects.

Keywords: risk, population, NPP, dose, age composition, damage, safety.

\section{Introduction}

Radiation plays a huge role in the development of civilization at this historical stage. Due to the phenomenon of radioactivity, a significant breakthrough was made in the field of medicine and in various industries, including energy. But at the same time, negative aspects of the properties of radioactive elements became more pronounced: it turned out that the effects of radiation on the body can have tragic consequences. This fact could not pass by the attention of the public. And the more it became known about the effect of radiation on the human body and the environment, the more controversial became the opinions about how much radiation should play in various spheres of human activity.

Over the past 20 years, substantial work has been done to reduce the risks and mitigate the effects of man-made emergencies. In this regard, nuclear power plants remain the source of radiation around which the most intense disputes are conducted, although they currently contribute very little to the total exposure of the population. Negative public opinion on nuclear power can be justified by the fact that the solution of problems of NPP risk analysis is carried out in conditions of considerable uncertainty. Moreover, despite the low probability of the most dangerous accident, the radiation effects may be significant and require close attention.

Thus, the task of clarifying the risk assessment of radiation exposure to the population, taking into account the age criterion as the most significant, becomes more relevant and determines the significance of this study.

\section{Review of risk assessment methods}

This chapter provides an overview of risk assessment methods. The chapter consists of two sections. Section one provides an overview of risk assessment methods, describes the terms and definitions required for risk assessments, and discusses the main quantitative risk indicators. Section two presents the methodology for calculating the level of exposure for different age groups of the population.

\section{Risk assessment methodology}

In 2004, by order of the Minister of Emergencies of Russia [1], a typical safety data sheet of a hazardous facility was approved. On its basis, a safety data sheet was developed for the critical (dangerous) object of Rosatom [2].

To solve the problems of risk assessments in 2004, it was decided to develop a "Methodology for assessing risk indicators for managing the safety of critical (hazardous) facilities of ROSATOM. The methodology developed in 2010 [3] established a unified approach to the assessment of risk indicators for NPPs with reactors of various types, recommendations for organizing and conducting risk assessments, and documenting the results of risk assessments in accordance with the requirements of the safety data sheet.

In 2007, the Methodological Guidelines (MG) "Rapid Assessment of Doses to the Population in Case of Radioactive Pollution of the Territory by Air" [4] were developed, defining methods for calculating the level of exposure to members of various population groups (depending on age, profession, type of dwelling). In the risk assessment for safety data sheets of Russian NPPs, these MGs were not included.

The study was based on works [5, 6] implemented by Rosenergoatom Concern JSC in the framework of the preparation of safety data sheets for Russian NPPs (in particular, Rostov and Kalinin NPPs). The risk assessment of an accident at a nuclear power plant is carried out according to the procedure for conducting a Level 3 PSA using the FOOD computer program, which allows the calculation of radiation doses to personnel and the public at various distances from the source of the radionuclide release. The probabilities of the occurrence of various emergency scenarios are calculated according to the MU for conducting risk analysis of hazardous production facilities [7]. Physical indicators of the risk of radiation exposure on personnel and population are estimated in accordance with [8] According to [8]:

1. The radiation sources that create are not considered: individual annual effective dose of not more than $10 \mu \mathrm{Sv}$;

collective effective annual dose of not more than 1 person-Sv;

2. It is accepted that radiation in a collective effective dose of 1 man-Sv leads to potential damage equal to a loss of 1 man-year of life;

3. To assess the harm to health from radiation in small doses, both the effects of irradiation of individual organs and tissues of the body, differing in radiosensitivity, and the irradiation of the whole organism as a whole are taken into account. The averaged value of the risk coefficient used to establish dose limits for personnel and the public was assumed to be 0.051 / Sv.

The distribution of radionuclides in the environment from the emission source to the direct impact on humans or the environment can be divided into three areas:

- Emissions to the atmosphere;

- $\quad$ Liquid discharges into rivers, reservoirs or seas; Disposal of waste in the ground.

The considered methodology for assessing NPP risk indicators is devoted to the first direction of propagation, and 
specifically to the effects of air emissions on the population and personnel.

- As initial data for the calculation of risk for personnel and the population are used: Frequencies of consequences in design and beyond design basis accidents (calculated using probabilistic safety analysis (PSA));

- Estimation of the number of radionuclides involved in the design and beyond design basis accidents;

- Data on climatic conditions in the area of the NPP location: repetition of wind directions, average annual wind speed;

- Data on the population in the $100-\mathrm{km}$ NPP zone, population distribution by points.

Release of radionuclides into the environment is considered short-lived. When estimating the population exposure doses, three methods of exposure are taken into account:

direct inhalation;

exposure from a radioactive cloud;

exposure from a contaminated surface to the ground.

The assessment result of the accident radiation consequences on the population are:

absorbed dose of external irradiation of the whole body and internal irradiation of the thyroid gland during inhalation at the initial stage (first 10 days) of the accident;

- annual effective radiation dose

Early deaths among the population are excluded, because maximum individual absorbed doses do not reach the level of 1 Gray, and internal exposure of the thyroid gland during inhalation does not reach the level of 5 Gray, at which deterministic effects are possible.

In $[5,6]$, the assessment is made for an average adult with an average radiosensitivity. This provides a basis for studying the influence of age composition on estimates of radiation risk indicators of the population.

According to the results of calculations, indicators of radiation and economic risks from accidents for nuclear power plants are compared with $[8,9]$.

\section{Calculating Method of the exposure level for different age population groups}

In $[5,6]$, the radiation risk assessment is made for an average adult with an average radiosensitivity. According to [4], which regulates the process of rapid assessment of doses to the public during radioactive contamination of the territory by air, there is a significant difference in the transition factors from the absorbed radiation dose to the effective dose, reflecting the risk of radiation effects for different age groups.

\section{Estimation of the exposure level for different age population groups}

The following concepts are used for evaluation:

- Absorbed dose in a tissue or organ - the amount of ionizing radiation energy transferred to the tissue or organ;

Equivalent dose - absorbed dose in an organ or tissue multiplied by the corresponding weighting factor of this type of radiation, reflecting the ability to damage body tissues (the weighting coefficient of gamma radiation for biological tissue is taken to be unity);

- $\quad$ Effective dose - the value used as a measure of the risk of the occurrence of the remote effects of exposure of the entire human body and individual tissues and organs, taking into account their radiosensitivity.

Radioactive pollution of the environment is the starting point in the further chain of human exposure pathways: internal and external. The main ways of radioactive pollution of the environment are:

- release of radioactive substances into the atmosphere;

- discharge of radioactive substances into surface waters (rivers, lakes, etc.).

In this study, only the first pathway is considered.

Estimation of population exposure doses is carried out for three age groups:

for adults (over 18);

for school-age children (from 7 to 12 years old);

for preschoolers (from 1 to 2 years).

Evaluation of external exposure doses of the population is carried out for two directions of external exposure:

- $\quad$ exposure from a radioactive cloud;

irradiation from the underlying surface.

In general, the model of external exposure is based on the presence of a dose coefficient relating the concentration of radionuclides to the dose characteristic of the external radiation field or directly to the effective dose. This approach involves the use of measured data during radiation monitoring as source data: concentrations of individual radionuclides in the surface layer of air;

- surface contamination of the underlying surface by individual radionuclides.

The effective external dose for the $i$-th group of the population when exposed to a radioactive cloud $E_{i, a}^{\text {ext }}(\mathrm{mSv})$ is defined as:

$$
E_{i, a}^{e x t}=K_{i, a} \cdot T \cdot \sum_{k=1} e_{k}^{a} \cdot C_{k}^{a},
$$

where: $e_{k}^{a}$ is the dose coefficient determining the absorbed dose rate of gamma radiation from the $k$-th radionuclide at a height of $1 \mathrm{~m}$ above the underlying surface from the source in the form of a radioactive cloud, $(\mathrm{mGy} / \mathrm{h}) /\left(\mathrm{kBq} / \mathrm{m}^{3}\right)$; $/ \mathrm{m}^{3}$;

$C_{k}^{a}$ - the average concentration of the $k$-th radionuclide, $\mathrm{kBq}$

$T$ - the time of exposure from this source, hour;

$K_{i, a}$ is the coefficient of transition from the dose in the air to the effective dose for the $i$ th group of the population, $\mathrm{mSv} / \mathrm{mGy}$.

$K_{i, a}$ is assumed to be:

- $\quad 0.7 \mathrm{mSv} / \mathrm{mGy}$ - for adults;

$0.75 \mathrm{mSv} / \mathrm{mGy}$ - for schoolchildren;

$0.85 \mathrm{mSv} / \mathrm{mGy}$ - for preschoolers.

Based on Formula 1, we can assume that the effective dose of external exposure from a radioactive cloud linearly depends on the coefficient $\mathrm{K}_{\mathrm{i}, \mathrm{a}}$.

Similarly, the effective external dose of the i-th group of the population from a mixture of radionuclides dropped on the underlying surface, $E_{i, s}^{e x t}$, linearly depends on $K_{i, s}$ :

$$
E_{i, s}^{e x t}=K_{i, s} \cdot T \cdot \sum_{k=1} e_{k}^{S} \cdot \sigma_{k}^{S},
$$

where: $\mathrm{e}_{k}^{s}$ is the dose coefficient determining the absorbed dose rate of gamma radiation from the $\mathrm{k}$-th radionuclide at a height of $1 \mathrm{~m}$ from a flat isotropic source located at the air-toground boundary, $(\mathrm{mGy} / \mathrm{hour}) /\left(\mathrm{kBq} / \mathrm{m}^{2}\right)$;

$\sigma_{k}^{S}-$ surface activity of the k-th radionuclide on the soil, $\mathrm{kBq} / \mathrm{m}^{2}$;

$T$ - the time elapsed since the end of the radioactive fallout, hour;

$K_{i, s}$ is the transition coefficient from the dose in air at a height of $1 \mathrm{~m}$ above the underlying surface to the effective dose for the i-th group of the population, $\mathrm{mSv} / \mathrm{mGy} . K_{i, S}$ is assumed to be:

$0.75 \mathrm{mSv} / \mathrm{mGy}$ - for adults;

$0.80 \mathrm{mSv} / \mathrm{mGy}$ - for schoolchildren;

$0.90 \mathrm{mSv} / \mathrm{mGy}$ - for preschoolers.

When a population is exposed to a man-made environment, the characteristics of the radiation field change. It is possible to take into account this change in the calculations using the location factors $L_{j}$, defined as the ratio of the dose rate in the air at point $\mathrm{j}$ within the settlement or in its area due to man-made 
gamma radiation, to a similar value over the open virgin soil Human behavior in the radiation field is described using the factors of behavior $F_{i j}$, depending on the season and representing a fraction of the time during which representatives of the $i$-th population group are located at the $\mathrm{j}$-th point of the locality.

In the study we neglect these parameters due to the lack of anthropogenic characteristics of the territory around the NPP. The study of the influence of place factors and factors of population behavior is also of scientific value and can be considered as part of a separate work.

The following initial data are used in assessing the internal exposure doses of the population:

concentration of radionuclides in the air;

duration of inhalation.

The value of the effective dose from inhalation in the i-th group of the population can be calculated using the expression:

$$
E_{i}^{i n h}=10^{-6} \cdot V_{i} \cdot T \cdot \sum_{k=1} C_{a}^{k} \cdot h_{i, i n h}^{k},
$$

where: $h_{i, i n h}^{k}$ is the dose coefficient for the $i$-th group of the population and the $k$-th radionuclide, $\mathrm{Sv} / \mathrm{Bq}$;

$C_{a}^{k}$ is the average concentration of the $k$ th radionuclide in the surface air layer during the passage of the radioactive cloud, $\mathrm{kBq}$ $/ \mathrm{m}^{3}$;

$T$ - time of exposure from the source, hour;

$V_{i}$ - respiration intensity of representatives of the $i$-th group of the population, $\mathrm{m} 3$ / hour.

Based on Formula 3, we can assume that the effective dose from inhalation depends linearly on $h_{i, i n h}^{k}$ and $V_{i}$.

Data on $h_{i, \text { inh }}^{k}$ are known only for the most irradiated critical age groups of the population [8], therefore, it is impossible to differentiate according to a given coefficient for different age groups.

The value of the equivalent dose to the thyroid gland in the i-th group of the population from inhalation $H_{i, t h r}^{i n h}$ is calculated as:

$$
H_{i, t h r}^{i n h}=V_{i} \cdot T \cdot \sum_{k=1} C_{a}^{k} \cdot h_{i, t h r}^{k}
$$

where: $h_{i, t h r}^{k}-$ dose coefficient for the i-th population group and the $\mathrm{k}$-th radionuclide (iodine or tellurium), $\mathrm{mSv} / \mathrm{kBq}$;

$C_{a}^{k}$ is the average concentration of the $k$ th radionuclide in the surface air layer during the passage of the radioactive cloud, $\mathrm{kBq}$ $/ \mathrm{m}^{3}$

$T$ - time of irradiation from this source, hour;

$V_{i}-$ respiration intensity of representatives of the $i$-th group of the population, $\mathrm{m} 3$ / hour.

On the basis of Formula 4, we can assume that the equivalent dose of irradiation of the thyroid gland linearly depends on $h_{i, t h r}^{k}$ and $V_{i}$.

The effective dose of internal exposure of the population due to the oral intake of the $\mathrm{k}$-th radionuclide in the body is calculated by measuring its specific activity in the consumed food products. Sampling and measurements are carried out at times $t_{1}$ and $t_{2}$, where $t_{1}$ and $t_{2}$ are the time elapsed since to the start of consumption of contaminated food (it is assumed that this moment coincides with the end of radioactive fallout). In the study, we neglect this indicator, because We consider the indicators of the effective dose of radiation in the early phase of the accident (the first 10 days).

The total effective dose for the i-th group of the population living in the territory that has been contaminated with a mixture of radionuclides is equal to the sum of doses of external exposure from the radioactive cloud $E_{i, a}^{e x t}$ and deposition on the underlying surface $E_{i, s}^{e x t}$, internal dose due to inhalation of radionuclides $E_{i}^{i n h}$ :

$$
E_{i}^{\text {sum }}=E_{i, a}^{e x t}+E_{i, s}^{e x t}+E_{i}^{i n h}, \mathrm{м} 3 \mathrm{~B}
$$

The equivalent dose of the thyroid gland for the i-th group of the population is equal to the sum of doses due to inhalation of iodine radionuclides $H_{i, t h r}^{i n h}, \mathrm{mSv}$.

\section{NPP Radiation Risk Assessments}

In this section, a quantitative assessment of the physical and economic indicators of radiation risk for the Rostov and Kalinin nuclear power plants taking into account the age composition of the population.

\section{Radiation Risk Assessments at Rostov NPP}

Rostov NPP is located in the Rostov region, $12 \mathrm{~km}$ from the city of Volgodonsk on the bank of the Tsimlyansk reservoir. Volgodonsk is located in the eastern part of the Rostov region, between two million-plus cities - Rostov-on-Don and Volgograd.

Rostov NPP is one of the largest energy companies in the south of Russia, providing about $15 \%$ of the annual electricity generation in the region.

The electrical capacity of the three existing power units is 3.1 GW. All reactors (four power units) are VVER-1000 water-towater power reactors. Power units of the Rostov NPP were commissioned in 2001, 2009, 2015 and 2018.

Estimation of the potential radiative forcing of radionuclide emissions (RS) is made on the basis of population data by points and distance from Rostov NPP from $3 \mathrm{~km}$ to $30 \mathrm{~km}$, and the average population density outside the $30 \mathrm{~km}$ zone to $100 \mathrm{~km}$ is also estimated (Table 1 and Fig. 1).

Table 1. Population distribution in the zone with a radius of $100 \mathrm{~km}$ around the Rostov NPP

\begin{tabular}{|l|c|c|c|c|c|c|c|c|}
\hline \multirow{2}{*}{ Rumba } & \multicolumn{7}{|c|}{ Distance from NPP, km } & \multirow{2}{*}{ Total people } \\
\cline { 2 - 8 } & $\mathbf{3 - 1 0}$ & $\mathbf{1 0 - 1 5}$ & $\mathbf{1 5 - 2 0}$ & $\mathbf{2 0 - 3 0}$ & $\mathbf{3 0 - 4 0}$ & $\mathbf{4 0 - 5 0}$ & $\mathbf{5 0 - 1 0 0}$ & \\
\hline North & - & - & 315 & 868 & 1044 & 1342 & 11186 & 14755 \\
\hline Northeast & 860 & - & 88 & 390 & 1044 & 1342 & 11186 & 14910 \\
\hline East & 860 & - & 620 & 512 & 1044 & 1342 & 11186 & 15564 \\
\hline Southeast & 230 & - & 591 & 791 & 1044 & 1342 & 11186 & 15184 \\
\hline South & 230 & 345 & 193 & 1076 & 1044 & 1342 & 11186 & 15416 \\
\hline Southwest & - & 595 & 74952 & 15432 & 1044 & 1342 & 11186 & 104553 \\
\hline West & - & 250 & 75574 & 26780 & 1044 & 1342 & 11186 & 116176 \\
\hline Northwest & - & - & 1071 & 12622 & 1044 & 1342 & 11186 & 27265 \\
\hline Total & 2180 & 1190 & 153404 & 58571 & 8352 & 10736 & 89488 & 323823 \\
\hline
\end{tabular}

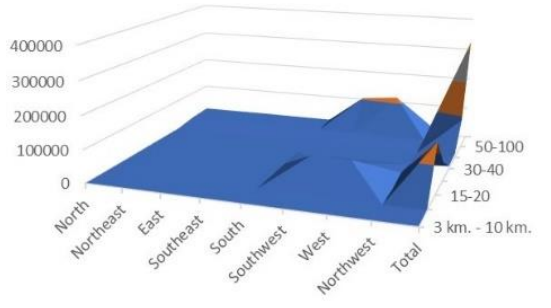

$=0-100000=100000-200000=200000-300000=300000-350000$

Fig. 1. Population distribution in the zone with a radius of 100 $\mathrm{km}$ around the Rostov NPP

On the basis of [5], the accident "Disruption of the steam line in the protective shell of the NPP with the design value of leakage in the steam generator from the 1 st circuit to the 2 nd" was chosen as the design basis accident (implementation frequency 5.6 $10^{-5}$ $1 /$ reactor-year), as a beyond design basis accident "Deenergizing NPPs with a diesel generator failure and BRU-A" (frequency $\vartheta=3.8 \cdot 10^{-8} 1 /$ reactor-year).

The share of absorbed internal radiation in the total absorbed radiation is approximately $98 \%$. Based on this, and also taking into account the uncertainty of age coefficients when calculating the effective dose of external exposure, it was proposed to adjust the total effective dose by the coefficient for internal exposure $h_{i, t h r}^{k} \cdot V_{i}$ (formula 4).

Based on the obtained coefficients, the average total effective annual doses of external and internal exposure (formula 5) of three population groups in each of the ring segments of rumba are calculated. The calculation results are shown in Table 2 and Fig. 2.

Table 2. Estimation of average total effective annual doses of external and internal exposure of three population groups in each of the ring segments of rumba during the 
most dangerous accident at the Rostov NPP

\begin{tabular}{|c|c|c|c|}
\hline Distance from NPP, km & $\boldsymbol{E}_{1}^{\text {sum }}, \mathbf{m S v}$ & $\boldsymbol{E}_{2}^{\text {sum }}, \mathbf{m S v}$ & $\boldsymbol{E}_{3}^{\text {sum }}, \mathbf{m S v}$ \\
\hline $3-10$ & 10,52 & 20,76 & 26,75 \\
\hline $10-15$ & 1,91 & 3,77 & 4,86 \\
\hline $15-20$ & 1,04 & 2,06 & 2,65 \\
\hline $20-30$ & 0,60 & 1,18 & 1,52 \\
\hline $30-40$ & 0,32 & 0,63 & 0,82 \\
\hline $40-50$ & 0,20 & 0,40 & 0,52 \\
\hline $50-100$ & 0,11 & 0,21 & 0,27 \\
\hline
\end{tabular}

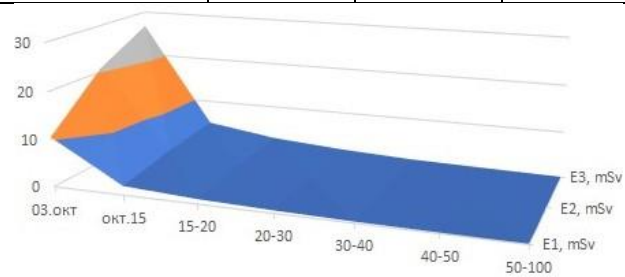

$=0-10=10-20=20-30$

Fig. 2. Estimation of average total effective annual doses of external and internal exposure of three population groups in each of the ring segments of rumba during the most dangerous accident at the Rostov NPP

To estimate the number of the N_i population in each age group, data from the 2010 All-Russian Population Census for the Rostov Region were used, according to which the adult population is $85 \%$, schoolchildren ( $7-12$ years old) - $8 \%$, preschool children (1-2 years) - 7\%.

To assess the radiation effects of the accident on the various groups of the population in 8 points in the $100 \mathrm{~km}$ zone around the Rostov NPP, the following calculations were made:

- $\quad$ collective dose $E_{i}^{c o l}$, man $\cdot \mathrm{Sv} /$ year;

- late deaths, $N_{i}^{d t h}$;

- $\quad$ collective risk of late death, $R_{i}^{d t h}$.

$$
E_{i}^{\text {col }}=N_{i} \cdot E_{i}^{\text {sum }}
$$

For the most complete assessment of the harm that can be caused to health as a result of radiation in small doses, the damage is determined by quantifying both the effects of irradiation of individual organs and tissues of the body, differing in radiosensitivity to ionizing radiation, and of the organism as a whole. In accordance with the linear non-threshold theory of dose risk dependence of stochastic effects generally accepted in the world, the magnitude of the risk is proportional to the radiation dose and is related to the dose through the linear radiation risk coefficients.

$$
\begin{aligned}
& N_{i}^{d t h}=k \cdot E_{i}^{c o l} \\
& R_{i}^{d t h}=\vartheta \cdot N_{i}^{d t h}
\end{aligned}
$$

where $\vartheta=3.8 \cdot 10^{-8} 1 /$ reactor-year.

The economic damage $G_{i}$ as a result of harm to the health of the population, which can manifest itself in the form of stochastic effects (radiogenic cancer and hereditary diseases), is estimated by the formula:

$$
G_{i}=z \cdot E_{i}^{c o l}
$$

where $z$ is the monetary equivalent of the loss of one personyear of life of the population, is assumed to be equal to 0.3 million rubles / person-Sv.

\section{Radiation Risk Assessments at Kalinin NPP}

Kalinin NPP is located on the southern shore of Lake Udomlya and near the city of the same name. The town of Udomlya is located north of the Tver region, $120 \mathrm{~km}$ from the city of Tver. The Kalinin NPP has four power units with VVER1000 type reactors. The 1 st and 2 nd power units were launched in 1984 and 1986, the 3rd and 4th power units in 2004 and 2012, respectively. The potential radiative forcing of radioactive substances is estimated on the basis of population data by points and the distance from Kalinin NPP from 3 to $30 \mathrm{~km}$, and the average density of the population living at a distance of 30-100 $\mathrm{km}$ is estimated (Table 3 and Fig 3 ).

Table 3. Population distribution in a zone with a radius of
$100 \mathrm{~km}$ around Kalinin NPP

\begin{tabular}{|c|c|c|c|c|c|c|c|c|c|}
\hline \multirow{2}{*}{ Rumba } & \multicolumn{8}{|c|}{ Distance from NPP, km } & $\begin{array}{c}\text { Total } \\
\text { people }\end{array}$ \\
\cline { 2 - 10 } & $\mathbf{3 - 5}$ & $\mathbf{5 - 1 0}$ & $\mathbf{1 0 - 1 5}$ & $\mathbf{1 5 - 2 0}$ & $\mathbf{2 0 - 3 0}$ & $\mathbf{3 0 - 4 0}$ & $\mathbf{4 0 - 5 0}$ & $\mathbf{5 0 - 1 0 0}$ & 30816 \\
\hline North & 0 & 251 & 170 & 258 & 295 & 241 & 3090 & 26511 & 308 \\
\hline Northeast & 0 & 157 & 88 & 266 & 203 & 189 & 3090 & 26511 & 30504 \\
\hline East & 0 & 254 & 177 & 464 & 301 & 287 & 9499 & 52549 & 63531 \\
\hline Southeast & 0 & 377 & 296 & 549 & 421 & 407 & 3090 & 38354 & 43494 \\
\hline South & 8505 & 325 & 246 & 498 & 370 & 356 & 3090 & 74155 & 87545 \\
\hline Southwest & 16158 & 318 & 230 & 598 & 370 & 356 & 52342 & 26511 & 96883 \\
\hline West & 7339 & 336 & 227 & 562 & 370 & 356 & 3090 & 50964 & 63244 \\
\hline Northwest & 0 & 227 & 176 & 379 & 279 & 265 & 3090 & 81242 & 85658 \\
\hline Total & 32002 & 2245 & 1610 & 3574 & 2609 & 2447 & 80381 & 376797 & 501665 \\
\hline
\end{tabular}

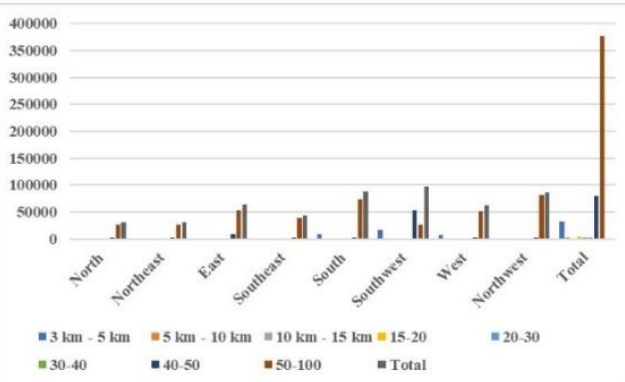

Fig. 3. Population distribution in a zone with a radius of $100 \mathrm{~km}$ around Kalinin NPP

Based on [6], the "Medium primary circuit leak" accident (with a sales frequency of $4.2 \cdot 10^{-4} 1 /$ reactor-year) was selected as the most likely accident at the Kalinin NPP, with the refusal of the ECCS high and low pressure" (with a frequency $\vartheta=$ $1.47 \cdot 10^{-6} 1$ / reactor-year).

The share of absorbed internal irradiation in the total absorbed irradiation is approximately $97 \%$. Proceeding from this, and also taking into account the uncertainty of age coefficients when calculating the effective external dose, it was proposed to adjust the total effective dose by the coefficient for internal exposure $h_{i, t h r}^{k} \cdot V_{i}$ (Formula 4 ).

Calculating the coefficient $h_{i, t h r}^{k} \cdot V_{i}$ we get (Fig. 4):

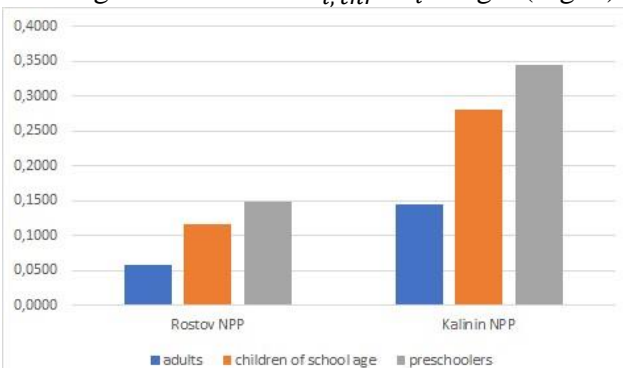

Fig. 4. Coefficient $\boldsymbol{h}_{\boldsymbol{i} \text {, } \boldsymbol{k} \boldsymbol{r}} \cdot \boldsymbol{V}_{\boldsymbol{i}}$ for Rostov and Kalinin NPP

Or the ratio relative to the indicators for the adult population (Fig. 5):

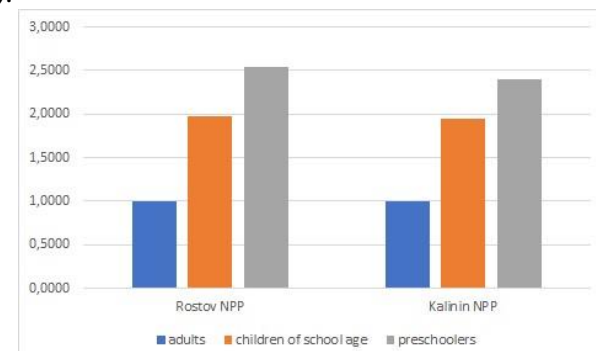

Fig. 5. The indicators for the adult population for Rostov and Kalinin NPP

Using these coefficients, we calculate the average total effective annual doses of external and internal exposure (Formula 5) of three population groups in each of the ring segments of rumba.

To estimate the number of the N_i population in each age group, data from the 2010 All-Russian Population Census for the Tver Region were used, according to which the adult population 
is $85 \%$, schoolchildren (7-12 years old) - $8 \%$, preschoolers (1-2 years) $-7 \%$.

To assess the radiation effects of the accident on various groups of the population, the following calculations were performed at 8 points in the $100 \mathrm{~km}$ zone around the Kalinin NPP: collective dose $E_{i}^{c o l}$, man $\cdot \mathrm{Sv} /$ year; the number of late deaths, $N_{i}^{d t h}$; collective risk of late death, $R_{i}^{d t h}$.

The economic damage $G_{i}$ as a result of harm to the health of the population, which can manifest itself in the form of stochastic effects (radiogenic cancer and hereditary diseases), is estimated by the formula (9).

Comparison of the obtained damage indicators with those calculated without taking into account the age composition of the population confirms that the adjustment for the age composition gives an order of magnitude higher indicators of the risk of exposure of the population. The emergency exposure of the population, taking into account the adjustment, is below the levels that are subject to radiation safety requirements. Nevertheless, the results obtained make it possible to argue that the age composition of the population must be taken into account when developing measures to reduce the risk and mitigate the consequences for the population and, in particular, for the most sensitive age groups (1-12 years old).

\section{Results}

According to the results of the study, the author achieved the following results:

1. Review of existing approaches to assessment of population radiation risk and risk indicators;

2. Identification of the degree of influence of age composition on the calculation of radiation doses of the population at different irradiation routes (external and internal);

3. Modification of the formula for calculating the annual effective dose of radiation of the population in the ring segment of the Rumba taking into account the age composition;

4. Calculation of the annual effective dose of different age groups for Rostov and Kalinin NPP with VVER-1000 Tapa reactors;

5. Calculation of physical and economic indicators of damage of different age groups of the population for Rostov and Kalinin NPP.

\section{Conclusions}

According to the results of calculations, indicators of radiation and economic risks from accidents for Rostov and Kalinin NPPs are within the limits allowed by the requirements [8] and [9]. Nevertheless, there is a significant deviation in the positive direction for all indicators in the calculation, taking into account the age composition. This determines the need to take into account the results obtained to assess the radiation risk.

The study makes a significant contribution to the development of methods for assessing the radiation risk of nuclear power plants and can serve as an incentive to further study the influence of external factors such as population composition, geographical features, anthropogenic environmental change, etc. on risk assessment.

Refined estimates of physical and economic indicators will significantly reduce planning errors in developing measures to reduce the risk and mitigate the consequences of accidents at nuclear power plants.

\section{Thanks}

The study was carried out within the framework of grant 1907-00455 «Development of models, algorithms and software for solving the problems of safety and risk assessment at nuclear power plants during beyond design basis accidents with the release of sources of thermal neutrons with low flux density».

\section{References:}

1. On approval of a typical safety data sheet of a hazardous object: [Order of the Emergencies Ministry of Russia No. 506 of November 4, 2004]. - M., 2004. - 1 p.

2. Safety data sheet of the critical (dangerous) object of Rosatom: [order of the Ministry of Emergency Situations of Russia No. 506 of November 4, 2004]. - M., 2006. - 9 p.

3. Methodology for assessing risk indicators for managing the safety of critical (hazardous) facilities of ROSATOM: [Methodology: Approved by the First Deputy Director General of the State Atomic Energy Corporation ROSATOM for the nuclear weapons complex on March 29. 2016]. - M., 2016. - 253 p.

4. Rapid assessment of radiation doses to the public in case of radioactive contamination of the territory by air: [Guidelines MU 2.6.1.2153-06: approved by the Chief State Sanitary Doctor of the Russian Federation on 04.12.2006]. - M., 2007. - 90 p.

5. Kabanov, L.P., Berberova, M.A., and others. Risk assessment of a reference nuclear power plant with a VVER (operating unit of a nuclear power plant with a VVER 1000): a report on research and development reg. № 1821OT10 // International Nuclear Safety Center - M. 2010. - $132 \mathrm{p}$

6. Zhukov, I.V., Berberova, M.A., and others. Developing a list of safety management measures and assessing risk indicators for Stage 2 of the Kalinin NPP with a WWER1000 reactor (V-320): a research report on reg. No. 2339OT12 // International Nuclear Safety Center - M., 2012. - 109 p.

7. Procedural Guidelines for Risk Assessment of Hazardous Industrial Facilities. Series 27. Issue 16. - M.: Closed JointStock Company "Scientific and Technical Center for Industrial Safety Research", 2016. - 56 p.

8. SanPiN 2.6.1.2523-09. Radiation safety standards (NRB99/2009). Approved by the Resolution of the Chief State Sanitary Doctor of the Russian Federation // No.47 of 07.07.2009. - M., 2009. - 75 p.

9. Recommendations of the International Commission on Radiation Protection from 2007: [ICRP Publication 103: approved March 2007]. - Moscow: Proceedings of the ICRP, 2009. $344 \mathrm{p}$. 